\title{
Sınıf Öğretmeni Adaylarının Çokgenlerin Kritik Özelliklerine ilişskin Alan Bilgisi ${ }^{1}$
}

\author{
Prof. Dr. Asuman Duatepe-Paksu \\ Pamukkale Üniversitesi-Türkiye \\ aduatepe@pau.edu.tr
}

\begin{abstract}
:
Nicel araştırma yöntemlerinden tarama modelinin kullanıldığı bu çalışmada sınıf ögretmeni adaylarının çokgen kavramına yönelik alan bilgilerinin belirlenmesi amaçlanmıştır. Çalışmanın verileri basit seçkisiz örnekleme yöntemi ile seçilen Ege Bölgesinde bir üniversitenin Temel Eğitim Bölümü Sınıf Öğretmenliği Anabilim dalında okuyan 60 öğretmen adayından toplanmıştır. Veri toplama amacıyla Žilková (2011) tarafından geliştirilen Çokgen Tanıma Testi kullanılmıştır. Veriler öğretmen adaylarının çokgenin kritik özelliklerini ne ölçüde bildiğini belirlemek üzere değerlendirilmiştir. Bulgular katılımaların neredeyse tamamının üçgen dışındaki dışbükey çokgenleri çokgen olarak nitelendirebildiğini ancak içbükey çokgenleri tanımada bu oranın düştügüunü göstermiştir. Öğretmen adaylarının dörtte birinin çokgenin en az 3 kenarlı olması ve kapalı olması gerektiğini bilmedikleri belirlenmiştir. Ayrıca katılımcıların yarısından çoğu verilen kenarları doğrusal olmayan şekillerden bazılarını çokgen olarak nitelendirmiştir. Araştırmacılara öğretmen adaylarının belirlenen bu alan bilgisi eksikliğinin nedenlerinin belirlenmesine yönelik çalışmalar planlamaları önerilebilir.
\end{abstract}

Anahtar Kelimeler: Alan bilgisi, sınıf öğretmeni adayı, çokgen, çokgenin kritik özellikleri

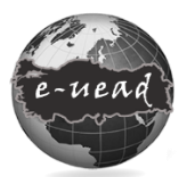

E-Uluslararası Eğitim Araştırmaları Dergisi Cilt: 9, Sayt: 3, 2018, ss. 34-46

DOI: 10.19160/ijer.398063

Gönderim : 12.03 .2018

Revizyon 1: 12.05 .2018

Kabul: 01.09.2018

\section{Suggested Citation}

Duatepe-Paksu, A. (2018). Sınıf Öğretmeni Adaylarının Çokgenlerin Kritik Özelliklerine illişkin Alan Bilgisi, E-Uluslararası Eğitim Araştırmaları Dergisi, Cilt 9, Sayı 3, 2018, ss. 34-46 DOI: 10.19160/ijer.398063

\footnotetext{
${ }^{1}$ Bu çalışma 4th International Eurasian Educational Research Congress 11-14 Mayıs 2017 Pamukkale Üniversitesi/Deniizli'de sunulan bildirinin genişletilmiş halidir.
} 


\section{GiRis}

Öğretmenin sahip olması gereken yeterlikler içerisinde alan bilgisi temel öğelerden biridir. Shulman (1987: s.8), öğretmen bilgisini alan bilgisi, genel pedagoji bilgisi, müfredat bilgisi, pedagojik alan bilgisi, öğrenci özellikleri bilgisi, eğitimsel ortam ve şartlar bilgisi, eğitimsel amaçlar, hedefler, değerler ile bunların felsefi ve tarihsel temelleri bilgisi olarak yedi başlık altında incelemiştir. Bu başılılardan ilki olan alan bilgisi genel olarak öğretmenin zihnindeki bilgi miktarı ve organizasyonu olarak tanımlanmaktadır (Shulman, 1986). Alan bilgisine matematik dersi özelinde bakıldığında Ball'un (1991) bir öğretmenin sahip olması gereken matematik alan bilgisini matematiksel konuların epistemolojisi, bu konuların aktarılmasında kullanılacak tanım, ilişkiler, kurallar, formüller ve ispat yöntemleri olarak tanımladığı görülebilir. Öğretim programına ilişkin bilgi ya da alanın öğrencilere aktarılmasına yönelik olan pedagojik alan bilgisi için öncelikle alan bilgisinin güçlü olması gerekmektedir.

Öğretmenin matematik alan bilgisi içinde özel olarak geometri alan bilgisi önemli bir yer tutar. Günümüzde geometri alan bilgisinin öneminin artmasının altında çeşitli nedenler yatmaktadır. Bilişim teknolojilerinin gelişimiyle geometrinin animasyonlardan küresel konumlama sistemlerine uzanan yeni kullanım alanlarının ortaya çıkması bu nedenlerin önde gelenlerindendir (van de Walle, Karp, ve Williams, 2010). İçinde bulunduğumuz çağın getirdiği yenilikler bu durumun önümüzdeki yıllarda da süreceğine işaret etmektedir.

Bu çalışmada öğretmen adaylarının geometri alan bilgisinin temel konularından olan çokgenler kavramına yönelik alan bilgileri incelenmiştir. Matematikte çokgen düzlemde herhangi üçü doğrusal olmayan $n$ tane noktayı ikişer ikişer birleştiren doğru parçalarının oluşturduğu kapalı şekil olarak tanımlanır (Aydın, Camus ve Kaya, 2018; Öz, Koşanser, Emir, Ata, Parlar ve Yaymacl, 2018). Hershkowitz (1990) tanımlarda yer alan kritik özelliklerin öğrenenlerin o tanıma ait örnekleri belirlemesinde anahtar olduğunu ifade etmiştir. Yukarıda verilen çokgen tanımına göre çokgenin kritik özellikleri en az 3 kenarlı olması, kenarlarının doğrusal olması ve kapalı olmasıdır.

Çokgen konusu bu kavramın adıyla adlandırılmasa da okul öncesi eğitimden itibaren öğrencinin karşısına çıkar (MEB, 2013). Anasınıfı düzeyinde üçgen ve dörtgen örnekleriyle informel olarak karşılaşan öğrenciler ilköğretimin ilk kademesinde çokgen örnekleriyle formel olarak karşılaşır (MEB, 2017). İlkokul öğrencilerinin çokgenle formel olarak karşılaştığı bu dönemde bu kavramla ilgili bilgi ve becerileri doğru bir şekilde edinebilmeleri için öğretmenlerinin de bu konudaki bilgilerinin eksiksiz ve sağlam olması gerekmektedir. Aşağıda alanyazında rastlanan bu konuda yapılmış çalışmaların derlemesi sunulmuştur.

\section{ilgili Araştırmalar}

Alanyazında öğretmen adaylarının geometri alan bilgisi konusunda eksiklikleri olduğunu ortaya koyan çalışmalar mevcuttur (Altaylı, Konyalıoğlu, Hızarcı, ve Kaplan, 2014; Ayvaz, Gündüz, ve Bozkuş, 2017; Baltacı ve Baki, 2017; Baran, Bozkuş ve Gündüz, 2015; Bütüner ve Filiz, 2016; Çakmak, Konyalıoğlu ve Işık, 2014; Çetin ve Dane, 2004; Duatepe-Paksu, 2013; Gunčaga, Kopáčová, ve Duatepe-Paksu, 2013; Fujita ve Jones, 2006; Gökkurt ve Soylu, 2016; Günhan, 2014; Gündüz ve Bulut, 2017; Karadeniz, Baran, Bozkuş, ve Gündüz, 2015; Karakuş ve Erşen, 2016; Kartal ve Çınar, 2017; Köğce, 2015; Marchis, 2012; Pickreign, 2007; Umay, Duatepe ve Akkuş, 2005; Zilkova, 2011; Žilková, Gunčaga, ve Kopáčová, 2015). Aşağıda sunulan çalışmalar çokgenin kritik özellikleri olan en az 3 kenarlı olması, kenarlarının doğrusal olması ve kapalı olması konusunda öğrencilerin zorlukları olduğunu göstermiştir (Akuysal, 2007; Başışık, 2010; Berkün, 2011; Ergün, 2010; Lipovec, 2009).

Lipovec (2009) altmış beş dördüncü sınıf öğrenciyle yaptığı çalışmasında öğrencilerin çokgenin kenarının doğrusal olmak zorunda olmadığını düşündüklerini belirlemiştir. Bu öğrenciler kenarları eğrilerden oluşan bazı şekilleri çokgen olarak kabul etmişlerdir. Çalışmaya katılan 
öğrencilerin yarısından fazlası iç bükey çokgenleri çokgen olarak nitelendirmemiştir. Benzer şekilde Başışık (2010) beşinci sınıf öğrencileri ile gerçekleştirdiği çalışmasında öğrencilerin içbükey çokgenleri çokgen olarak nitelendirmediklerini ancak kenarları doğrusal olmayan şekilleri çokgen olarak kabul ettiklerini belirlemiştir. Bunlara ek olarak bu çalışmada öğrencilerin çokgenin üçten fazla kenarı olması gerektiğini düşündükleri ortaya çıkmıştır. Bu çalışmayla benzer sonuçlar elde eden Berkün (2011) beşinci sınıf öğrencilerinin yanı sıra yedinci sınıf öğrencileri ile de çalışmıştır. Başışık'ın (2010) çalışmasına benzer şekilde öğrencilerin içbükey çokgenleri çokgen olarak algılamadıklarını belirlemiştir. Bu öğrenciler de çokgenlerin üçten fazla kenarı olması gerektiği yanılgısına sahiptirler ve kenarları doğrusal olmayan şekilleri de çokgen olarak kabul etmişlerdir. Yine yedinci sınıflarla Akuysal'ın (2007) gerçekleştirdiği çalışmada öğrencilerin yamuk, paralelkenar, dikdörtgen, kare ve üçgeni çokgen olarak algılamadıkları, bir şeklin çokgen olması için en az beş kenara sahip olması gerektiğini düşündükleri ortaya çıkmıştır.

Ülkemizde bu konuda gerçekleştirilen bir başka araştırmada Ergün (2010) yedinci sınıf öğrencilerinin çokgenleri tanıma, tanımlama ve sınıflama biçimlerini değerlendirme konusunda çalışmıştır. Bu çalışmada öğrencilerin çokgen imgesini tanıdıklarını ancak çokgen olma koşullarını net bir şekilde bilmediklerini ortaya konmuştur. Ayrıca çokgen çizimleri yaparken hiçbir öğrencinin iç bükey çokgen çizmediği belirlenmiş öğrencilerin çokgen imgesinin yalnızca dış bükey çokgenden ibaret olduğu ifade edilmiştir. Bunların yanı sıra Ergün (2010) öğrencilerden bazılarının yalnızca düzgün çokgenleri çokgen olarak kabul ettiklerini ve yalnızca dörtgeni çokgen olarak kabul ettiklerini ortaya koymuştur.

Çokgenlere ilişkin öğretmen alan bilgisinin incelendiği çalışmalar ise farklı sonuçlar ortaya koymuştur. Carreño ve diğerleri (2013) öğretmek için matematik bilgisinin alt boyutlarına ilişkin yaptıkları çalışmada bir ortaokul öğretmen adayının çokgenin elemanlarına, kritik özelliklerine ve tanımına ilişkin alan bilgisini incelemişlerdir. Çokgen tanımını "kenarları doğrusal olmayan üç veya daha fazla noktanın birleşimi ile oluşan, kapalı ve düz sınır içinde kalan alan" biçiminde yapan öğretmen adayı çokgenin kritik özelliklerinden en az üç kenarlı olması ve kapalı olması gerektiğini açıkça ifade etmiştir. Öğretmen adayı tanımında doğrudan kenarların doğrusal olması gerektiğine değinmemesine rağmen çokgen örnekleri oluştururken kenarları doğrusal şekiller çizmiştir.

Zilkova (2011) sınıf öğretmeni adaylarının geometri alan bilgilerinin belirlendiği çalışmasında öğretmen adaylarına çokgen olan ve olmayan çeşitli şekiller sunmuş ve her bir şeklin çokgen olup olmadığının işaretlenmesini istemiştir. Çalışmada öğretmen adaylarının kapalı olmayan şekilleri de çokgen olarak işaretlediği belirlenmiştir. Ayrıca öğretmen adayları kenarları doğrusal olmayan ancak köşeleri olan şekilleri de çokgen olarak işaretlemişlerdir. Diğer taraftan öğretmen adayları üçgen ve dörtgenleri çokgen olarak işaretlememişlerdir.

Bu konuda ülkemizde yapılan çalışmada Kartal ve Çınar (2017) otuz üç ortaokul matematik öğretmeni adayının çokgenlere ilişkin alan bilgilerini incelemişlerdir. Çalışmada yalnızca bir öğretmen adayı çokgeni tamamen doğru bir biçimde tanımlamıştır. Öğretmen adaylarının çokgen tanımına ilişkin ifadeleri incelendiğinde, doğru tanım ifadesine en yakın olarak on öğretmen adayının çokgeni üç veya daha fazla kenarlı kapalı şekil olarak tanımlayarak kenarlarının doğrusallığını ifade etmediği görülmüştür.

\section{Araştırmanın Amacı}

Bu çalışma genel anlamda sınıf öğretmeni adaylarının geometrinin önemli kavramlarından olan çokgen ile ilgili alan bilgilerinin ne düzeyde olduğunun belirlenmesini amaçlamaktadır. Öğretmen adaylarının çokgenlere yönelik alan bilgisi çokgenin kritik özelliklerini bilme kapsamında ele alınmıştır. Araştırma sorusu "Öğretmen adayları çokgenlerin kritik özelliklerini belirleme durumları nedir?" olarak belirlenmiştir.

Çokgenler konusu hem içinde farklı çokgen çeşitlerini ve bunlar arasındaki ilişkileri içermesi hem de sonrasında prizmalar, piramitler, çok yüzlüler gibi geometrik cisimlerin anlaşılmasında 
gerekli temel konulardan olması bakımından önemli bir yere sahiptir. Ayrıca öğretmenlerin geometri alan bilgisinin öğrencilerinin konuya ilişkin bilgi ve becerilerini doğrudan etkilediği (Clements, 1999) düşünüldüğünde geleceğin öğretmenlerinin alan bilgilerinin belirlenmesi onların bu konudaki eksikliklerin giderilmesi yolunda ilk adım olacaktır.

Alanyazında öğrencilerin çokgenin kritik özelliklerini belirleme durumlarını içeren çalışmalar (Akuysal, 2007; Başışık, 2010; Berkün, 2011; Ergün, 2010; Lipovec, 2009) ve ortaokul matematik öğretmeni adaylarının çokgen bilgisine ilişkin çalışmalar (Carreño ve diğerleri; 2013; Kartal ve Çınar, 2017) bulunmaktadır. Bu konuda sını öğretmeni adaylarının çokgen bilgisine yönelik ulaşılan çalışma Zilkova (2011) tarafından Slovak örneklem üzerinde gerçekleştirilmiş, ülkemizdeki sınıf öğretmeni adaylarının çokgenlerin kritik özelliklerini belirleme durumlarına yönelik bir çalışmaya rastlanmamıştır. Çokgen konusuyla öğrencinin ilk tanışmasının ortaokul yıllarından önce olduğu düşünüldüğünde bu konuda sınıf öğretmeni adayları üzerinde bir çalışma gerçekleştirilmesinin gerekliliği hissedilmiştir.

\section{YÖNTEM}

Bu çalışmanın yürütülmesinde geçmişte ya da halen mevcut bir durumu var olduğu şekliyle betimlemeyi amaçlayan araştırma yaklaşımı olan tarama yöntemi kullanılmıştır. Bir konuya ya da olaya ilişkin katıımcıların görüşlerinin ya da ilgi, beceri, yetenek, tutum vb. özelliklerinin çalışıldığı genellikle diğer araştırmalara göre daha büyük örneklemler üzerinde yapılan araştırmalara tarama araştırmaları denir (Büyüköztürk, Kılıç-Çakmak, Akgün, Karadeniz ve Demirel, 2018). Bu yöntemde çok sayıda elemandan oluşan bir evrende, evren hakkında genel bir yargıya varmak için evrenin tümü ya da ondan alınacak bir grup örnek ya da örneklem üzerinde tarama yapılmaktadır (Karasar, 2002: 77-79).

\section{Evren ve Örneklem:}

Çalışmanın evreni Ege Bölgesinde bir üniversitenin Temel Eğitim Bölümü Sınıf Öğretmenliği Anabilim dalında okuyan son sınıf 143 öğretmen adayıdır. Bu evrenden basit seçkisiz örnekleme yöntemi ile belirlenen 60 sınıf öğretmeni adayı ise bu araştırmanın örneklemini oluşturmaktadır. Katılımcılar sınıf öğretmeni yetiştirme programındaki matematikle ilgili olan Temel Matematik ve Matematik Öğretimi derslerinin tamamını almış son sınıf öğrencileridir. Bu derslerin içeriklerinde temel düzlem geometri bilgileri, temel geometrik kavramlar, tanımlar, özellikler ve öğretimi; temel geometrik şekiller, cisimler ve öğretimi gibi bu çalışmanın konusuyla ilgili kavram ve süreçlere yer verilmektedir. Katıımcıların öğretmen yetiştirme programında yer alan geometri alan bilgisini geliştirebilecek tüm dersleri tamamlamış olmaları nedeniyle, gelecekteki öğrencilerine geometri öğretmeye hazır oldukları varsayılabilir.

\section{Veri toplama aracı}

Veri toplama amacıyla Žilková (2011) tarafından öğretmen adaylarına uygulanmak üzere geliştirilen Çokgen Tanıma Testi kullanıımıştır. Bu testte öğretmen adaylarına Şekil 1'de verilen 20 şekil sunulmuş, bu şekillerden çokgen olanların işaretlenmesi istenmiştir. Verilen şekillerin dokuzu dışbükey üçü içbükey olmak üzere 12 'si çokgendir. Dışbükey çokgenlerin ikisi üçgen, dördü dörtgen, biri beşgen, biri altıgen ve biri sekizgendir. Diğer sekiz şekil değişik nedenlerle çokgen olma koşulunu taşımamaktadır. İki şekil kapalı olmaması, altı şekil ise kenarları doğrusal olmaması nedeniyle çokgen değildir. Test araştırmacı tarafından öğretmen adaylarının bir dersleri öncesi uygulanmış, uygulamada süre kısıtlamasına gidilmemiştir. Testin bu uygulamadaki Cronbach alfa güvenirlik katsayısı 0.863 olarak hesaplanmıştır. 

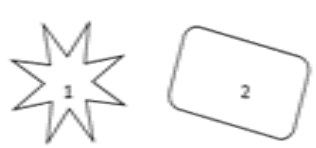

]
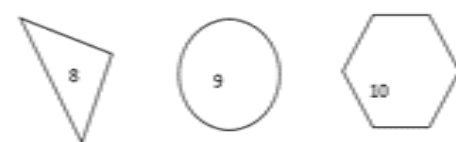

[ ]
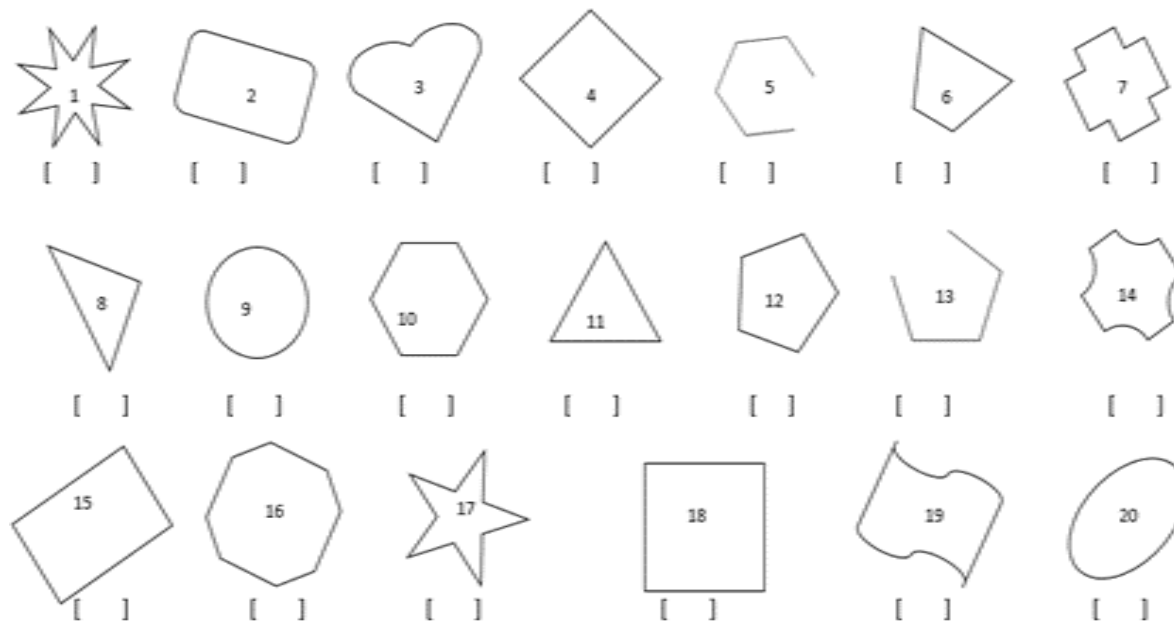

$\left[\begin{array}{lll}1 & 1\end{array}\right.$

[ ]

[ ]

[ ]
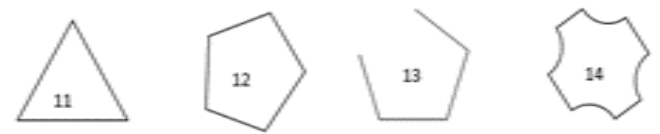

$\left[\begin{array}{ll}1 & ]\end{array}\right.$

[ ]
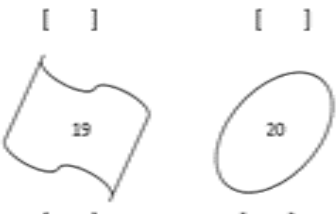

[ ]

Şekil 1. Çokgen Tanıma Testinde yer alan şekiller

\section{Verilerin Analizi}

Verilerin analizinde testteki şekillerden çokgen olan ve olmayan şekillerin doğru olarak tanınma oranları belirlenmiştir. Bu amaçla her bir şekil için doğru yanıt sayısı frekansı ve yüzdesi hesaplanmıştır. Elde edilen değerler çokgenlerin kritik özellikleri çerçevesinde incelenmiştir.

\section{BULGULAR}

Bulguların sunumunda öncelikle öğretmen adaylarının verilen şekiller içinde yer alan 12 çokgeni tanıma düzeyleri açıklanmıştır. Bu aşamada çokgenlerin tanınmasında onların içbükeydışbükey olma özelliklerinin dikkate alınıp alınmama durumları ve çokgeni belirlemede kenar sayısının etkili olup olmadığına ilişkin bulgular sunulmuştur. Sonraki kısımda öğretmen adaylarının çokgen olmayan sekiz şekilden birini/birkaçını seçmesi durumuna göre onların çokgenlerin kritik özelliklerinden kapalılık ve kenarların doğrusallığını dikkate alma oranları ortaya çıkarılmıştır.

\section{Öğretmen Adaylarının Çokgenleri Tanıma Düzeyleri}

Öğretmen adaylarına verilen 12 çokgenin dokuzu $(4,6,8,10,11,12,15,16$ ve 18 numaralı şekiller) dışbükeydir. Bu çokgenler Şekil 2'de verilmiştir. Şekilde de görüldüğü gibi dışbükey çokgenlerin ikisi $(8,11)$ üçgen, dördü $(4,6,15,18)$ dörtgen, biri $(12)$ beşgen, biri $(10)$ altıgen ve biri (16) sekizgendir.
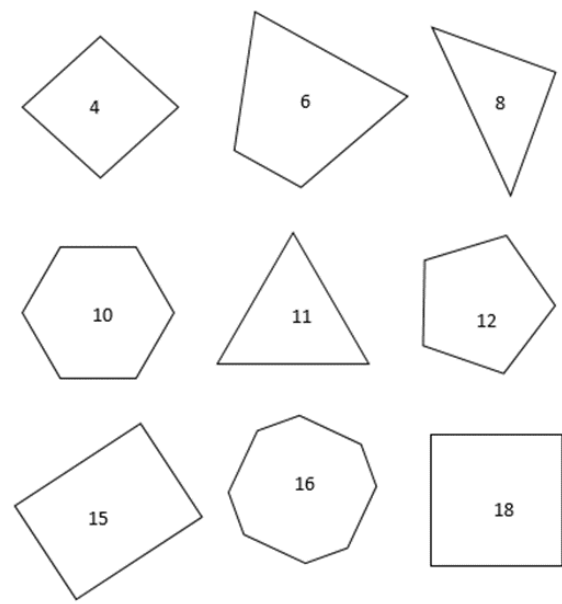

Şekil 2. Dışbükey çokgenler 
Öğretmen adaylarının verilen bu dışbükey şekilleri çokgen olarak belirleyip belirleyememe durumları Tablo 1'de görülebilir. Öğretmen adaylarının verilen şekilleri çokgen olarak nitelendirme yüzdesi incelendiğinde en düşük başarı oranının 91.7 olduğu görülmektedir. Bu yüzdeye bakarak katılımcıların dörtgen, beşgen, altıgen ve sekizgenleri çokgen olarak tanıma başarılarının oldukça iyi olduğu söylenebilir. Ancak öğretmen adaylarının verilen üçgenleri (8 ve 11) çokgen olarak tanıma durumlarına bakıldığında başarı yüzdesinin her iki şekil için de 83.3'e düştüğü görülmektedir. Buradan bazı öğretmen adaylarının çokgenin kritik özelliklerinden olan en az 3 kenarlı olması özelliğini bilmedikleri, dolayısıyla üçgenin de bir çokgen olduğunu fark etmedikleri söylenebilir.

\section{Tablo 1.}

Öğretmen adaylarının dışbükey çokgenleri tanıma sıklı̆ı ve yüzdesi [f(\%)]

\begin{tabular}{llll}
\hline şekil numarası & doğru & yanlış & boş \\
\hline 4 & $56(93.3)$ & $2(3.3)$ & $2(3.3)$ \\
6 & $57(95)$ & $2(3.3)$ & $1(1.7)$ \\
8 & $50(83.3)$ & $6(10)$ & $4(6.7)$ \\
10 & $59(98.3)$ & 0 & $1(1.7)$ \\
11 & $50(83.3)$ & $5(8.3)$ & $5(8.3)$ \\
12 & $57(95)$ & $1(1.7)$ & $2(3.3)$ \\
15 & $56(93.3)$ & $3(5)$ & $1(1.7)$ \\
16 & $57(95)$ & $1(1.7)$ & $2(3.3)$ \\
18 & $55(91.7)$ & $3(5)$ & $2(3.3)$ \\
\hline
\end{tabular}

Öğretmen adaylarına verilen çokgenlerden üçü $(1,7,17)$ içbükeydir. Bu içbükey çokgenler Şekil 3'te sunulmuştur.
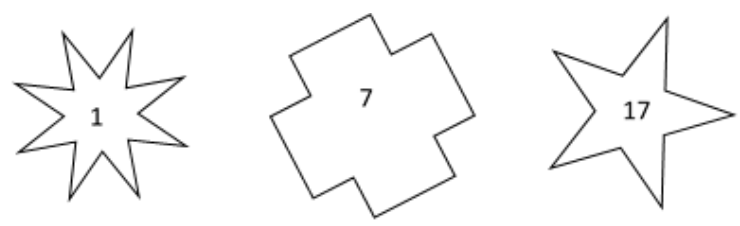

Şekil 3. içbükey çokgenler

Verilen içbükey şekillerin öğretmen adayları tarafından çokgen olarak tanıma durumları Tablo 2'de yer almaktadır. Tabloda verilen yüzdeler değerlendirildiğinde öğretmen adaylarının içbükey çokgenleri belirlemede dışbükey çokgenleri belirlemede olduğu kadar başarılı olmadıkları görülebilir. Dışbükey çokgenler için 98.3'e çıkan doğru cevap yüzdesi içbükey çokgenler için 76.7 ile 81.7 aralığında değişmektedir.

Tablo 2.

Öğretmen adaylarının içbükey çokgenleri tanıma sıklığı ve yüzdesi [f(\%)]

\begin{tabular}{llll}
\hline \multicolumn{4}{c}{ şekil numarası } \\
\hline & 1 & 7 & 17 \\
\hline doğru & $49(81.7)$ & $46(76.7)$ & $49(81.7)$ \\
yanıış & $9(15)$ & $7(11.7)$ & $8(13.3)$ \\
boş & $2(3.3)$ & $7(11.7)$ & $3(5)$ \\
\hline
\end{tabular}




\section{Öğretmen Adaylarının Çokgen Olmayan Şekilleri Tanıma Düzeyleri}

Öğretmen adaylarına verilen şekillerden 8'i kapalıık ve kenarların doğrusal olması özelliklerini sağlamama nedeniyle çokgen olma koşulunu taşımamaktadır. Şekil 4'te kapalı olmaması nedeniyle çokgen olarak nitelendirilemeyecek olan şekiller sunulmuştur.

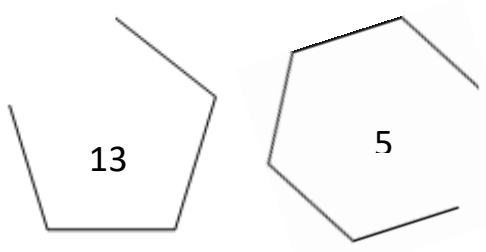

Şekil 4 Kapalı olma koşulunu sağlamayan şekiller

Öğretmen adaylarının verilen kapalı olmayan şekillerin çokgen olmadığını belirleyip belirleyememe durumları Tablo 3'te verilmektedir. Tabloda sunulan yüzdeler değerlendirildiğinde öğretmen adaylarının bu şekillerin çokgen olmadığını doğru olarak belirleme yüzdesinin her iki şekil için de \% 75 olduğu görülebilir. Çokgenin kapalı olması gerektiği kritik koşulunun bu oranda bilinmemesi öğretmen adaylarının bu konudaki alan bilgilerinin zayıf olduğuna işaret etmektedir.

Tablo 3.

Öğretmen adaylarının kapalı olmayan şekillerin çokgen olmadığını doğru olarak niteleme sıklığıve yüzdesi [f(\%)]

\begin{tabular}{lll}
\hline & \multicolumn{2}{l}{ şekil numarası } \\
\hline & 5 & 13 \\
\hline doğru & $45(75)$ & $45(75)$ \\
yanlış & $5(8.3)$ & $5(8.3)$ \\
boş & $10(16.7)$ & $10(16.7)$ \\
\hline
\end{tabular}

Öğretmen adaylarına verilen çokgen olmayan şekillerden altısı $(2,3,9,14,19$ ve 20) kenarları doğrusal olmaması nedeniyle çokgen olma koşulunu taşımamaktadır. Bu şekiller Şekil 5 'te sunulmuştur.

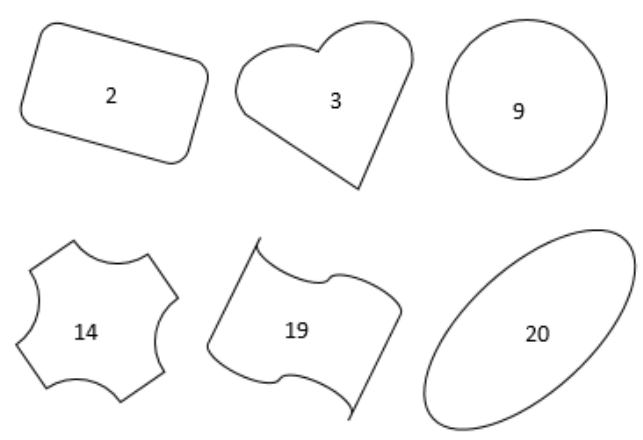

Şekil 5. Kenarların doğrusal olması koşulunu sağlamayan şekiller

Öğretmen adaylarının kenarları doğrusal olmayan şekillerin çokgen olmadığını belirleyip belirleyememe durumları Tablo 4'te sunulmuştur. Tabloda sunulan yüzdeler öğretmen adaylarııın bu şekillerin çokgen olmadığını belirleme yüzdesinin \% 41.7 ile \% 71.7 arasında değiştiğini göstermektedir. Öğretmen adaylarından yarısından çoğunun çokgenin kenarlarının doğrusal olma koşulunu bilmemesi düşündürücüdür. Bu değerlere bakılarak öğretmen adaylarının çokgenin kenarlarının doğrusal olması gerektiği konusundaki bilgilerinin kapalıığına ilişkin bilgilerine göre daha zayıf olduğu söylenebilir. 
Tablo 4.

Öğretmen adaylarının kenarları doğrusal olmayan şekillerin çokgen olmadığını doğru olarak niteleme sıklı̆ıı ve yüzdesi [f(\%)]

\begin{tabular}{lllllll}
\hline \multicolumn{6}{l}{ şekil numarası } \\
\hline & 2 & 3 & 9 & 14 & 19 & 20 \\
\hline doğru & $33(55)$ & $43(71.7)$ & $35(58.3)$ & $25(41.7)$ & $40(66.7)$ & $41(68.3)$ \\
yanlış & $19(31.7)$ & $9(15)$ & $22(36.7)$ & $26(43.3)$ & $12(20)$ & $12(20)$ \\
boş & $8(13.3)$ & $8(13.3)$ & $3(5)$ & $9(15)$ & $8(13.3)$ & $7(11.7)$ \\
\hline
\end{tabular}

Çalışmada elde edilen bulgular özetlenecek olursa, katııımcı öğretmen adaylarının tamamına yakını üçgen dışındaki dışbükey çokgenleri çokgen olarak nitelendirebilmişken, neredeyse çeyreği içbükey çokgenleri çokgen olarak nitelememiştir. Öğretmen adaylarının dörtte birinin çokgenin en az 3 kenarlı olması gerektiğini bilmedikleri belirlenmiştir. Bu öğretmen adayları üçgeni bir çokgen olarak nitelememişlerdir. Ayrıca katılımcı öğretmen adaylarının dörtte biri kapalı olmayan şekilleri de çokgen olarak nitelendirmişlerdir. Öğretmen adaylarının en başarısız olduğu özellik çokgen olmanın diğer koşulu olan kenarların doğrusal olmasıdır. Verilen kenarları doğrusal olmayan şekillerden bazılarını öğretmen adaylarından yarısından çoğu çokgen olarak nitelendirmiştir.

\section{TARTIŞMA, SONUÇ VE ÖNERILER}

Bu çalışmada sınıf öğretmeni adaylarının çokgen kavramına yönelik alan bilgilerinin belirlenmesi amaçlanmıştır Bulgular katılımcı öğretmen adaylarının neredeyse tamamının üçgen dışındaki dışbükey çokgenleri çokgen olarak nitelendirebilmişken, içbükey çokgenler için bu oranın \% 76.7'de kaldığını göstermiştir. Bu bulgu Başışık (2010), Berkün (2011), Ergün (2010) ve Lipovec'in (2009) öğrenciler üzerinde yaptıkları çalışmaların sonuçlarıyla tutarlıdır. Alanyazındaki bu çalışmalarda öğrencilerin sahip oldukları bu yanılgıya öğretmen adaylarının da sahip olması çarpıcıdır.

Yukarıda da anlatıldığı gibi çokgenin kritik özellikleri (a) en az 3 kenarlı, (b) kapalı ve (c) kenarlarının doğrusal olmasıdır. Katılımcı öğretmen adaylarının dörtte birinin bu özelliklerden en az 3 kenarlı olması ve kapalı olması özelliğini bilmedikleri belirlenmiştir. Bu öğretmen adayları üçgeni de bir çokgen olarak nitelememişlerdir. Alanyazındaki çalışmalarda ilkokul ve ortaokul öğrencilerinin (Akuysal, 2007; Başışık, 2010; Berkün, 2011; Ergün, 2010) ve sınıf öğretmeni öğretmen adaylarının Zilkova'nın (2011) sahip olduğu belirlenen bu yanılgıya da öğretmen adaylarında rastlanması çalışmanın diğer bir çarpııı sonucudur.

Çokgen olmanın diğer koşulu olan kenarların doğrusal olması koşulu ise öğretmen adaylarının en zayıf olduğu kısımdır. Verilen kenarları doğrusal olmayan şekillerden bazılarını öğretmen adaylarından yarısından çoğu çokgen olarak nitelendirmiştir. Bu bulgu da Başışık (2010), Berkün (2011) ve Lipovec'in (2009) ilkokul ve ortaokul öğrencileriyle, Kartal ve Çınar'ın (2017) ve Zilkova'nın (2011) öğretmen adaylarıyla yaptıkları çalışmaların sonuçlarıyla tutarlıdır.

Öğretmen adaylarının öğrencilerin sahip olduğu yanılgıları göstermesi onların lise eğitimlerinde ve sonrasında öğretmen yetiştirme programında aldıkları eğitimlerde çokgenlere ilişkin alan bilgilerini geliştiremediklerini göstergesi olabilir. Öğretmen adaylarının çokgenleri tanıma, çokgenlere ilişkin örnek olan ve örnek olmayan durumları inceleme, çokgenleri sınıflama gibi etkinliklerle öğretmen yetiştirme programında yer alan derslerde yeterince karşılaşmamaları olabilir. Öğretmen yetiştirme programında yer alan matematik ders içeriklerinde bu konularda uygulamalı çalışmaların yer alması, geleceğin öğretmenlerinin geometri alan bilgisi açısından gelişmelerine yardımcı olacaktır. Araştırmacılara öğretmen adaylarının bu konuda belirlenen alan bilgisi eksikliğinin nedenlerinin tespit edilmesine yönelik çalışmalar planlamaları önerilebilir. Böylece bu eksikliklerin nasıl giderilebileceğine yönelik olarak somut önerilerde bulunmak mümkün olabilecektir. 


\section{KAYNAKÇA}

Akuysal, N. (2007). Ilköğretim 7. SınıfÖğrencilerinin 7. Sınıf Ünitelerindeki Geometrik Kavramlardaki Yanılgıları. Yayınlanmamış Yüksek Lisans Tezi, Selçuk Üniversitesi Eğitim Bilimleri Enstitüsü

Altaylı, D., Konyalıŏlu, A. C., Hızarcı, S., ve Kaplan, A. (2014). Illköğretim matematik öğretmen adaylarının üç boyutlu cisimlere ilişkin pedagojik alan bilgilerinin incelenmesi. Middle Eastern and African Journal of Educational Research, 10, 4-24.

Aydın, N., Camus, A., Kaya, M. (2018) Ortaöğretim Matematik 10 Ders Kitabı Aydın Yayıncılık Ankara

Ayvaz, Ü., Gündüz, N., ve Bozkuş, F. (2017). Understanding of Prospective Mathematics Teachers of the Concept of Diagonal. Journal on Mathematics Education, 8(2), 165-184

Ball, D. L. (1991). Research on teaching mathematics: Making subject-matter knowledge part of the equation J.E. Brophy (Eds.), Advances in research on teaching: Vol. 2. Teachers' knowledge of subject-matter as it relates to their teaching practice, (pp. 1-48) JAI Press, Greenwich, CT

Baltacı, S., ve Baki, A. (2017). Bağlamsal öğrenme ortamı oluşturmada GeoGebra yazılımının rolü: Elips Örneği, Ahi Evran Üniversitesi Kurşehir Eğitim Fakültesi Dergisi, 18(1), 429-449

Baran, T., Bozkuş, F., ve Gündüz, N. (2015). Difficulties of Prospective Elementary Mathematics Teachers' Regarding to Reflection Symmetry. Turkish Journal of Computer and Mathematics Education, 6(1), 117 138

Başışık, H. (2010). Ilköğretim 5. sınıf öğrencilerinin çokgenler ve dörtgenler konularındaki kavram yanılgılarının belirlenmesi Yayımlanmamış yüksek lisans tezi, Adnan Menderes Üniversitesi, Aydın.

Berkün, M. (2011). Illköğretim 5 ve 7. sınıf öğrencilerinin çokgenler üzerindeki imgeleri ve sınıflandırma stratejileri. Yayımlanmamış yüksek lisans tezi, Dokuz Eylül Üniversitesi, İzmir.

Bütüner, S. Ö., ve Filiz, M. (2016). Matematik Öğretmeni Adaylarının Dörtgenleri Sınıflandırma Becerilerinin İncelenmesi. Alan Eğitimi Araştırmaları Dergisi, 2(2), 43-56.

Büyüköztürk, S., Kılıç-Çakmak E., Akgün Ö., Karadeniz, S. ve Demirel F. (2018). Eğitimde Bilimsel Arastırma Yöntemleri (25. baskı). Ankara: Pegem Akademi

Carreño, E., Ribeiro, C. M., \& Climent, N. (2013). Specialized and horizon content knowledge-Discussing prospective teachers knowledge on polygons. Proceedings of the Eight Congress of European Mathematics Education, 2966-2975.

Clements, D. H. (1999). Teaching length measurement: Research challenges. School Science and Mathematics, 99(1), 5-11.

Çakmak, Z., Konyalıoğlu, A. C., ve Işık A. (2014). İlköğretim matematik öğretmen adaylarının üç boyutlu cisimlere ilişkin konu alan bilgilerinin incelenmesi. Middle Eastern and African Journal of Educational Research MAJER, 8, 28-44.

Çetin, O. F. ve Dane, A. (2004). Sınıf öğretmenliği III. sınıf öğrencilerinin geometrik bilgilere erişi düzeyleri üzerine, Kastamonu Eğitim Dergisi, 12(2), 427-436.

Duatepe-Paksu, A. (2013) Sınıf öğretmeni adaylarının geometri hazırbulunuşlukları, düşünme düzeyleri, geometriye karşı özyeterlikleri ve tutumları. Pamukkale Üniversitesi Eğitim Fakültesi Dergisi, 33, 203218.

Ergün, S. (2010). Ilköğretim 7. sınıf öğrencilerinin çokgenleri algılama, tanımlama ve sınıflama biçimleri. Yayınlanmamıs Yüksek Lisans Tezi DEÜ Eğitim Bilimleri Enstitüsü.

Fujita, T., \& Jones, K. (2006) Primary trainee teachers' understanding of basic geometrical figures in Scotland. Proceedings of the 30th Conference of the International Group for the Psychology of Mathematics Education, 3, 14-21.

Gökkurt, B. ve Soylu, Y. (2016). Ortaokul Matematik Öğretmenlerinin Matematiksel Alan Bilgilerinin İncelenmesi Prizma Örneği. Abant lizzet Baysal Üniversitesi Eğitim Fakültesi Dergisi 16(2), 451-482.

Gunčaga, J. Kopáčová, J. \& Duatepe-Paksu, A. (2013). A comparative Study: Turkish and Slovak Preservice Primary Mathematics Teachers' Skills about Symmetry. In Proceedings-SEMT'13 Tasks and tools in elementary mathematics, Prague: Charles University, pp. 99-107.

Günhan, B. C. (2014). An Investigation of Pre-Service Elementary School Teachers' Knowledge Concerning Quadrilaterals. Çukurova University. Faculty of Education Journal, 43(2), 137-154.

Gündüz, N., ve Bulut, A. S. (2017). Öğretmen Adaylarının Geometrik Cisimler Konusundaki Bilgi Düzeyleri, Problem Çözme Düzeyleri ve Tutumlarının İncelenmesi. İnönü Üniversitesi Eğitim Fakültesi Dergisi, 18 (2), 1-15.

Hershkowitz, R. (1990). Psychological aspects of learning geometry. In P. Nesher \& J. Kilpatrick (Eds.), Mathematics and Cognition (pp. 70-95). Cambridge: Cambridge University Press. 
Karadeniz, M. H., Baran, T., Bozkuş, F., ve Gündüz, N. (2015). Difficulties of prospective elementary mathematics teachers' regarding to reflection symmetry. Turkish Journal of Computer and Mathematics Education (TURCOMAT), 6(1), 117-138.

Karakuş F. ve Erşen, Z. B. (2016). Sınıf Öğretmeni Adaylarının Bazı Dörtgenlere Yönelik Tanımlama ve Sınıflamalarının İncelenmesi. Karaelmas Eğitim Bilimleri Dergisi, 4(1).38-49

Karasar, N. (2002). Bilimsel Araştırma Yöntemi, Nobel Yayın, Ankara.

Kartal, B. ve Çınar, C. (2017). Illköğretim Matematik Öğretmen Adaylarının Çokgenlere Dair Geometri Bilgilerinin İncelenmesi. Journal of Kırşehir Education Faculty, 18(2), 451-482.

Köğce, D. (2015). Conceptions and Concept Images of Prospective Mathematics Teachers in a Teacher Training Program Regarding Basic Mathematical Concepts. International J. Soc. Sci. and Education, Vol. 5(4), 678-706

Lipovec, A. (2009). Prototypical Reasoning in Developing Early Geometric Concepts. 3rd International Conference Curriculums of the Early and Compulsory Education. 12-14 November, Zadar, Croatia.

MEB (2013).Okul Öncesi Eğitim Programı Ankara: Milli Eğitim Bakanlığı.

MEB (2017). Matematik Dersi Öğretim Programı (İlkokul ve Ortaokul 1, 2, 3, 4, 5, 6,7 ve 8. Sınıflar). Ankara: Milli Eğitim Bakanlığı.

Marchis, I. (2012). Preservice Primary School Teachers' Elementary Geometry Knowledge, Acta Didactica Napocensia, 5(2), 33-40.

Öz, B., Koşanser, B., Emir, E., Ata, H., Parlar, H. F. ve Yaymacı, M. (2018). Ortaöğretim Fen Lisesi Matematik 10 Ders kitabı, Devlet Kitapları, Ankara

Pickreign, J. (2007). Rectangles and Rhombi: How Well Do Preservice Teachers Know Them? IUMPST: The Journal, 1, 1-7

Shulman, L. S. (1986). Those who understand: Knowledge growth in teaching. Educational Researcher, 15(2), 4-14.

Shulman, L. (1987). Knowledge and teaching: Foundations of the new reform. Harvard Educational Review, 57(1), 1-22.

Umay, A., Duatepe, A. ve Akkus-Çıkla, O. (2005). Readiness on Content of New Mathematics Curriculum, XIV. Proceedings of National Science and Mathematics Education Congress (pp. 456-458).

Van de Walle, J., Karp, K. S. \& Bay-Williams, J. M. (2010). Elementary and middle school mathematics: Teaching developmentally (Seventh edition). Boston, MA: Pearson Education

Žilková, K. (2011). Convex quadrilaterals and their properties in the training of teachers for primary education. Bratislava: Comenius University Press.ISBN 978-80-223-3085-5

Žilková, K., Gunčaga, J. \& Kopáčová, J. (2015). (Mis)Conceptions about geometric shapes in pre-service primary teachers. Acta Didactica Napocensia, 8(1), 27-35. 


\title{
The Preservice Elementary Teachers' Content Knowledge on the Critical Aspects of Polygons
}

\author{
Prof. Dr. Asuman Duatepe-Paksu \\ Pamukkale University-Türkiye \\ aduatepe@pau.edu.tr
}

\begin{abstract}
:
The purpose of this survey-study is to identify the preservice elementary teachers' content knowledge on critical attributes of polygons. Data of the study was collected from 60 preservice teachers of elementary education department of a university in Aegean region. In order to collect data Identifying Polygon Test constructed by Žilková (2011) was used. Findings revealed that almost all participants recognized convex polygons as polygons whereas less number of participants recognized concave polygons. Quarter of participants didn't know the fact that a polygon is a closed figure and has at least 3 sides. Furthermore more than half of the participants described the shapes that have non-linear sides as polygon. Recommendation for future researchers is to investigate the reasons of preservice teachers' difficulties on the content knowledge of this concept.
\end{abstract}

Keywords: Content knowledge, preservice teachers, polygons, critical attributes of polygons.

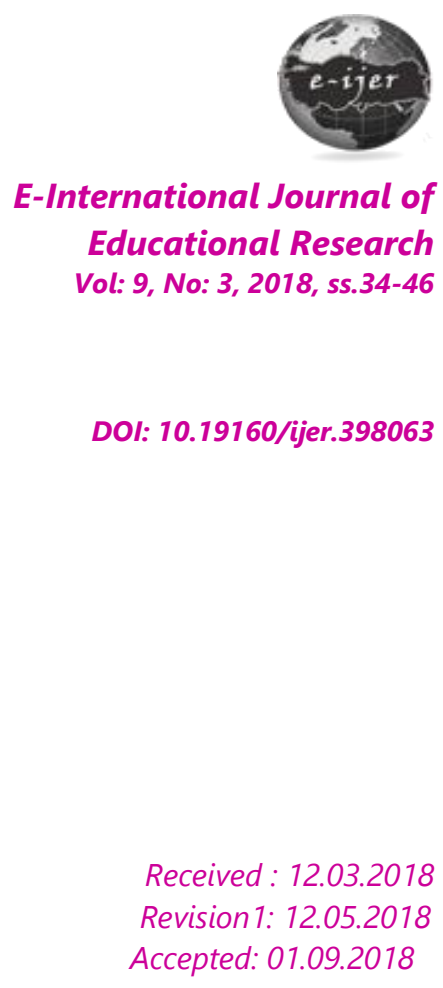

\section{Önerilen Atıf:}

Duatepe-Paksu, A. (2018). The Preservice Elementary Teachers' Content Knowledge on the Critical Aspects of Polygons, E-International Journal of Educational Research, Vol 9, No 3, 2018, pp. 34-46 DOI: 10.19160/ijer.398063 


\section{EXTENDED ABSTRACT}

Introduction: The purpose of this study is to identify the preservice elementary teachers' content knowledge on the critical aspects of polygons. This concept is important since it involves several geometrical shapes of school geometry like triangle, quadrilateral etc. and investigation of relations among various polygons. Moreover it is one of the fundamental concept to understand pyramid, prism and polyhedra. From this point of view, teachers who help students construct the strong knowledge about the polygon will be able to support the students get the fundamentals of the subsequent concepts. Considering that the teachers' content knowledge affects their students' knowledge and skills directly, identification of preservice teachers' content knowledge will be the first step towards eliminating their deficiency on the concept of polygons before they become a teacher.

Method: This study designed as a survey study that aims to describe current or past case as it is. Data of the study was collected from 60 preservice teachers of elementary education department of a university in Aegean region. Participants were seniors in their teacher-training program and already took the courses related to mathematics as Fundamentals of Mathematics and Mathematics Teaching. In other words participants were completed all required course which may help to develop their content knowledge on geometry, therefore it can be assumed that they are ready to teach geometry.

In order to collect data Identifying Polygon Test constructed by Žilková (2011) was used. In this test 20 shapes were displayed to the participants and they were instructed to select the polygons. Among those 20 shapes 12 of them were polygons ( 9 of them were convex and 3 of them were concave). Among the convex polygons, there were two triangles, four quadrilaterals, one pentagon, one hexagon and one octagon. The other 8 shapes were not polygons for several reasons. Two of the shapes were not polygons since they were not closed figures and six of the shapes are not polygons as had non-linear sides. The Cronbach alpha reliability coefficient was calculated as 0.863 .

Results: Findings revealed that almost all participants recognized convex polygons as polygons. On the other hand, the percentage of participants who recognized concave polygons was \% 76.7. Quarter of participants didn't know the fact that a polygon has at least 3 sides. These participants were not describe triangle as a polygon. Moreover, quarter of the participants didn't know the fact that a polygon is a closed figure. The other criteria for a polygon is linearity of sides. More than half of the participants described the shapes that has non-linear sides as polygons.

Discussion: In this study while almost all participants recognized convex polygons as polygons. The percentage of participants who recognized concave polygons was \%76.7. These findings were consistent with the studies Başışık (2010), Berkün (2011) and Lipovec (2009) who collected data on students. This result is dramatic considering teacher candidates has the same difficulties with the students.

The critical attributes of polygon are (a) at least 3 sides, (b) closed figure, and (c) linear sides Quarter of participants don't know the fact that a polygon has at least 3 sides. These participants were not describe triangle as a polygon. These findings were consistent with Başışı (2010) and Berkün (2011) who studied on elementary grade students. This was another dramatic result of the study.

The participants displayed the weakest results on the criteria of linear sides. Preservice teachers described most of the nonlinear shapes as polygons. More than half of the participants described the shapes that has non-linear sides as polygons. This finding is also concurrent with the studies of Başışık (2010), Berkün (2011) and Lipovec (2009) which showed similar results with the elementary grade students and Kartal and Çınar (2017) and Zilkova (2011) got similar results with the preservice teachers. 
The findings of the preservice teacher has the same difficulties with the elementary grades students imply that they did not get the necessary content knowledge on this concept during their high school years and teacher training program in their university years. They may not get necessary exposure to identifying polygons, example and non-example shapes, and classification of polygons. Enhancing teacher-training programs with this kind of content would be helpful for future teacher candidates.

Recommendation for future researcher is to investigate the reasons of preservice teachers' difficulties on the content knowledge of this concept so that it can be possible to make more sound suggestions to eliminate these difficulties. 